\title{
Introduction: The Politics of Resilience and Recovery in Mental Health Care
}

\author{
ALISON HOWELL \\ Humanitarian and Conflict Response Institute, The University of Manchester, \\ United Kingdom \\ JIJIAN VORONKA \\ Ontario Institute for Studies in Education, University of Toronto, Canada
}

\begin{abstract}
Recovery and resilience are now two of the central frameworks for organizing mental health care in the Western world. These frameworks posit that mental health "patients" can recover from their illnesses, and that resilience may be developed as a strength in order to avert or prevent so-called mental illness from the outset. The turn to "recovery" and to "resilience" has occurred in a context wherein mental health governance models based centrally on institutionalization had been the subject of much political resistance from those who have been psychiatrized, and also in a context of the retrenchment of state services through neo-liberal restructuring and cost-cutting measures. Large-scale deinstitutionalization in the second half of the 20th Century was met with the development of "Community-based" care as an alternative. Currently, those negotiating mental health services often find themselves subject to a mixture of institutional and community based mental health services, as well as other secondary institutional systems that offer mental health interventions (universities, work places, primary education, etc). Although such shifts apparently respond to the concerns expressed in the political resistance directed at total institutions (see Goffman, 1961), these new models of community care have arisen within a neo-liberal context, wherein social services are increasingly subject to prove their effectiveness through efficiency models that require community agencies to meet targets, ensure flow-through, and collect evidence-based data on their effectiveness. Simultaneously Western states are downloading their social responsibilities to the voluntary sector and to citizens themselves.
\end{abstract}


Whilst the concepts of resilience and recovery, then, originated in antiinstitutionalization movements, they have increasingly been incorporated into, and some would say co-opted by, medical reason and mental health policy. They have thus been re-figured: psychiatric experts now iterate that through recovery and resilience those who are deemed to have disordered minds can live "meaningful lives" despite the ostensible permanence of their "illness." This understanding works to deny the possibility of a kind of recovery that would place patients or "clients" outside the remit of medical authority. Whereas twenty years ago resilience and recovery were harnessed as organized frameworks for psychiatric survivors to avert the medical system through alternate means (including peer knowledge and support), they are now harnessed to incorporate psychiatric survivors into medical systems. They now work in ways that attempt to make psychiatric survivors responsible for their own adherence to prescribed ways of governing their interior lives, while at the same time leaving medical authority intact, since psychologists and psychiatrists have become experts in recovery and resilience. This raises serious questions about the social justice implications of these ostensibly humane approaches to mental health.

Approaching mental health through a social justice lens can reveal rich connections that highlight some of the most important themes in social justice research: inclusion, power, recognition, political economy, difference, equity and rights. And yet, the richness of this area of research has not been fully explored by social justice studies. This relates, in part, to the questionable notions of progress that surround psychology and psychiatry. With the march of time, we are told, these professions have become humane, liberal, and scientifically advanced. The sporadic attention to mental health in social justice studies also relates to the inadequacy of predominant approaches in the field. To be sure, any number of connections could be drawn between social justice and systems of mental health governance, but a limited number of approaches have been explored.

For instance, connections have been drawn between social justice and mental health through the analysis of the psychological consequences of injustices. Scholars working in this vein (see Shephard, 2002) argue that high rates of, for example, depression in women or schizophrenia in AfroCaribbean men, are the result of, or exacerbated by, societal unfairness. Mental illness, in this approach, is essentially figured as the result of social injustice. While laudable in attempting to raise social questions to the overarchingly individualistic disciplines of psychology and psychiatry, this approach, however, fails to question psychiatric authority and its diagnoses, including "depression" and "schizophrenia." The result is that this approach merely supplements a medical or biological model by providing complementary social explanations. It fails, however, to account for how marginalized people (such as the poor, colonial subjects, racialized people, queers and gender variant people, the disabled) tend to get disproportionately diagnosed or pathologized by the psychiatric profession, and how the psychiatric profession has been implicated in processes of colonialism, racism, sexism 
and heterosexism, as well as in disability and war-making (Howell, 2011; Metzl, 2010). A second line of inquiry into the connections between mental health and social justice focuses on fair and equal access to health services and welfare provision. Here, concerns over the decline of the welfare state and in particular of public health care provision are transposed onto questions of mental health, though again, without adequately questioning the authority of psychiatric practice. As such, questions about how "stigma" prevents the mentally ill from accessing services, or how socio-economic status, race and/or gender can impede or accelerate access to diagnoses and treatments are explored (Corrigan, Watson, Byrne, \& Davis, 2005; Cook \& Ngwena, 2007; Kronenfeld, 2008; WHO, 2008), but the authority of such diagnoses and treatments, and the psychiatric professions more generally, go largely unquestioned.

More recently scholarship located broadly in the field of critical disability studies has opened up new ways of thinking through the connections between social justice and mental health, precisely by challenging the norms that underpin the very value of "mental health" or "mental illness" as useful categories or ways of thinking about people. This scholarship takes inspiration, in particular, from re-invigorated activism that has developed out of anti-institutionalization and the service user/ consumer/survivor/expatient movements (Church, 1995; Crossley, 2006; Everett, 2000), as well as the mad movement (Morrison, 2005; Fabris, 2011), which is exploring the positive valuing of madness as a form of difference, particularly through activism carried out under the banner of Mad Pride. This coincides with developments in critical disability studies, where scholarship on the human rights of people living with disabilities is complemented by scholarship illustrating that disability is a matter not of deficit, but of difference in embodiment. It may further take inspiration from studies in the history and sociology of medicine that trace the very contingent rise of psychiatric and psychological authority (Hacking, 1995; Rose, 1998; Young, 1997), and also highlights a broader unease with bio-medicalism. At the same time, methods for peer/survivor research are increasingly being pursued, wherein survivors themselves contribute to knowledge production through user-controlled research (Beresford, 2002; Faulkner, 2004; Faulkner \& Nicholls, 1999; Godfrey, 2004; Sweeney, Beresford, Rose, Faulkner, \& Nettle, 2009).

Readers might best approach the articles in this special issue by suspending any belief in the authority of psychology and psychiatry, and questioning the bio-medicalism that deems some people normal, and others abnormal. Indeed, the articles included here help those interested in social justice to pose questions about sanism, which, for Perlin and Dorfman, "is inspired by (and reflects) the same kinds of irrational, unconscious, bias-driven stereotypes and prejudices that are exhibited in racist, sexist, homophobic and religiously- and ethnically-bigoted decision making" (Perlin \& Dorfman, 1993, p. 49). Further, we must query how and why it is that we are able to continue to approach the "thinking differently" of thoughts, experiences, behaviours and knowledge that is evoked through madness as inherently a 
problem that needs to be eradicated. Thus, the articles included here can be approached with an eye to viewing madness not as a deficit, but as a matter of difference, so as to view those who are subject to diagnosis as rightfully able to make choices about their engagements - or disengagements — with systems of mental health care, as well as medical and other authorities. This is not only a political stance: it can open up rich avenues for re-thinking the connections between mental health and social justice, and furthermore, for re-thinking social justice itself.

Indeed, the articles included here do just that, in particular by examining how the concepts of resilience and recovery are put to work in contemporary systems of mental health governance. Why resilience and recovery? The answer: precisely because these concepts appear so benign at first glance. Unpacking these notions can reveal the ways in which they are powerful tools in the governance of those deemed mentally ill, and also by extension, all citizens. In the case of recovery, what was once a term that was generated from the survivor movement, the focus was on "recovery in," whereas its current reiteration has transformed into "recovery from." To distinguish, the idea of "recovery in" presumes "that recovery must be grounded in a focus on survivor rights, peer support and recovering from the oppressive effects of being a mental patient" (Poole, 2011, p.15). However, as mental health systems have yielded to demands that they be more recovery-oriented, the social justice-orientation of "recovery in" has shifted into a model that has become "recovery from." Focusing on problematic neoliberal individualist principles including hope, empowerment, self-determination and responsibility, and the offering that with client-centred intervention and support, some can find cure, others "resume normalcy" while still others can build meaningful lives while living with mental illness (Poole, 2011), thus reinstating the expertise and authority of psychiatry and psychology. Importantly, "recovery from" has become a quantifiable measurable concept, model, and framework that practitioners are now busily receiving grants for and providing evidencebased research on, and through which they have found a place where they can remain central professionally.

As for resilience, the concept parallels the notion of recovery. Where recovery posits the ability of subjects to recover from an illness, the notion of resilience ostensibly recognizes the innate capacities of people to "bounce back" in the face of challenges or sources of distress. The capacity to be resilient is not, however, left to chance: psychologists have become authorities in instilling resilience, especially through the increasingly authoritative techniques such as cognitive behavioural therapy, or "positive psychology." These changes are deeply tied to broader austerity measures: getting citizens to be resilient in the face of challenges is not only cheap (in that it diverts patients out of public health care systems, in favour of self-help and positive thinking), it is also about aspiring to create a resilient citizenry, able to cope with uncertainty. This is a technology of looking inward: rather than confronting austerity measures or other matters of social justice through political action, citizens are enjoined to look inward, gather their strengths, 
and be resilient. Recovery and resilience, then, are notions deeply embedded with both the economic and the social imperatives of contemporary neoliberalism.

The articles included in this special issue engage these themes across a number of national settings, institutional spaces, and empirical sites, from universities to mental health commissions, to national policy in an international context. They focus, especially, on Canada, Ireland and the United Kingdom, where recent and significant changes in mental health governance have relied heavily on the notions of recovery and resilience, often to questionable effect. They deal, as we have said, with some of the most central themes in social justice studies. We have highlighted the question of difference above, but the question of inclusion also bears heavily on the discussion of mental health and social justice. In particular, many of the articles in the issue tackle the exclusion of users of psychiatric services and those who identify as mad from decision making, and the ways in which peers and service users can and should be meaningfully included in mental health provision, policy, and in the conduct of research. The articles also explore the pitfalls of inclusion, as recovery and resilience models within mental health systems now depend on inclusion as a best practice to prove that they are "doing the recovery model right," raising questions about what happens, both to service users and systems of power, in the process. Just as scholars in other fields (Chaun $\mathrm{Ku}, 2003$; Minh-ha, 1989; Spivak, 1999) have inquired about the appeal, process and result of the inclusion of Native Informants (Spivak, 1997), so too must we think through what limits and to what effect the conditions of mental health service user participation is constituted. As one of us has previously noted, the harnessing of the Mad Informant (Voronka, 2010) into mental health institutions has continuously failed to decentre the hegemony of biomedicalism. This raises question about meaningful participation, the management of diversity, what interests are being served by such inclusion, and whether playing the Mad Informant secures notions of individuals as mentally ill for medical professionals. Evoking such questions, as several of the following articles do, about practices of giving voice, inclusion, and storytelling, foregrounds the dangers involved in participation and inclusion, especially given that those who have had contact with the mental health system are often still denied basic human rights.

In putting together this special issue, then, we worked to include authors who identify as mad, as service users, as allies, and as activists in the field of mental health reform, and to privilege research that meaningfully involves such groups, or that tackles the broader discursive and policy frameworks within which notions of recovery and resilience circulate and gain power. In their article on "Uncovering Recovery" David Harper and Ewen Speed trace the increasing dominance of the recovery and resilience models across the psychiatric survivor movement, the third sector, and especially, mental health policy in the UK. They focus on how the recovery and resilience models of mental health individualize social problems, how they remain embedded in a notion of difference as deficit, obscuring structural causes of distress 
in the process. They thus raise significant questions about the social justice implications of the rise of the resilience and recovery models in mental health policy in the UK and beyond. Marina Morrow and Julia Weisser, in their article "Towards a Social Justice Framework of Mental Health Recovery," provide an analysis that foregrounds an understanding of power in the mental health care system, highlighting interlocking forms of oppression through an intersectional analysis. Based on a research project they conducted in Vancouver, Canada, which included both researchers and participants with lived experience of mental health service use, they raise pressing questions about the professional and bio-medical dominance over the meaning of recovery, to the exclusion of questions of social justice in the mental health field, such as the erosion of social welfare supports. By focusing on how user involvement in mental health service provision in Ireland is unfolding, Liz Brosnan's article on "Power and Participation" highlights the power relations inherent in attempts to include mental health service users. By drawing attention to the invisible aspects of power in operation in the recovery model, Brosnan draws attention to the ways in which social inequalities and injustices experienced by service-users are often overlooked in mental health service provision and policy. Katie Aubrecht's paper draws attention to the ways in which resilience discourses are harnessed in a particular institution: the university, and the ways in which resilience programming is strategically deployed so as to enjoin students to think positively about their experiences of university life and thus avert any experience of distress or disability. The aim of producing a healthy and "well" student body, however, fails to address inequalities amongst students, nor how such inequalities might be important in addressing student distress. Finally, the special issue concludes with an article written by a number of activists and advocates in the field of mental health reform and psychiatric survivor/mad pride activism who are working together as the Recovering our Stories Collective. It details an event which they organized in Toronto, Canada that sought to highlight some of the social justice issues involved in sharing personal stories of recovery with and for mental health professionals. It explores the ways in which the once transgressive act of sharing survivor narratives in order to "talk back to psychiatry" has now become a solicited commodity by mental health organizations in order to further their own stakeholder status as progressive, recovery-oriented service providers. As a collection, the articles help us think through some of the pressing political questions about social justice that have arisen with the adoption of the mantras of resilience and recovery in mental health governance.

\section{References}

Chaun Ku, J. S. (2003). Producing the Native Informant: Third World immigrant women's activism and self-making practices in the immigrant services sector (Unpublished doctoral dissertation). Toronto: Unpublished OISE/University of Toronto.

Church, K. (1995). Forbidden Narratives: Critical Autobiography as Social Science. Amsterdam, Overseas Publishers Association. 
Cook, R.J., \& Ngwena, C.G. (Eds.) (2007). Health and Human Rights. Aldershot, England: Ashgate.

Corrigan, P.W., Watson, A.C., Byrne, P., \& Davis, K.E. (2005). Mental Illness Stigma: Problem of Public Health or Social Justice. Social Work, 50(4), 363-368.

Crossley, N. (2006). Contesting Psychiatry: Social movements in mental health. New York: Routledge.

Everett, B. (2000). A Fragile revolution: Consumers and psychiatric survivors confront the power of the mental health system. Waterloo, On: Wilfred Laurier Press.

Fabris, E (2011). Tranquil Prisons: Chemical incarceration under Community Treatment Orders. Toronto: University of Toronto Press.

Goffman, E. (1961). Asylums: Essays on the social situation of mental patients and other inmates. New York: Doubleday Anchor.

Hacking, I. (1995). Rewriting the soul: Multiple personality and the sciences of memory. Princeton: Princeton University Press.

Howell, A. (2011). Madness in international relations: Psychology, Security and the Global Governance of Mental Health. London: Routledge.

Metzl, J. (2010). The protest psychosis: How schizophrenia became a black disease. Boston. MA: Beacon Press.

Minh-ha, T.T. (1989). Woman, native, other: Writing post-coloniality and feminism. Bloomington and Indianapolis, IN: Indiana University Press.

Poole, J. (2011). Behind the rhetoric: Mental health recovery in Ontario. Halifax \& Winnipeg: Fernwood.

Perlin, M.L., \& Dorfman, D.A., (1993). Sanism, social science, and the development of mental disability law jurisprudence. Behavioral Sciences and the Law, Vol. 11, 47-66.

Morrison, L.J. (2005). Talking back to psychiatry: The psychiatric consumer/survivor/ex-patient movement. New York, NY: Routledge.

Rose, N. (1998). Inventing ourselves: Psychology, power, and personhood. Cambridge: Cambridge University Press.

Spivak, G. C. (1997). Diasporas old and new. In A. Kumar (Ed.), Class Issues: pedagogy, cultural studies, and the public sphere. New York, NY: New York University Press: 87-116.

Spivak, G. C. (1999). A Critique of postcolonial reason: Towards a history of the vanishing present. Cambridge, MA: Harvard University Press.

Shephard, B. (2000). A War on Nerves. London: Jonathan Cape.

Sweeney, A., Beresford, P., Rose, D., Faulkner, A., \& Nettle, M. (2009). This is Survivor Research. Hay-on-Wye: PCCS.

Voronka, J. (June 2010). Consuming consumer narratives: a struggle over how to eat and how to be eaten. Opening plenary presented at Critical Inquiries. Centre for the Study of Gender, Social Inequities, and Mental Health, Simon Fraser University, Vancouver.

World Health Organization (2008). Mental Health Gap Action Programme: Scaling up care for mental, neurological, and substance use disorders. Geneva: WHO Press.

Young, A. (1997). The harmony of illusions: Inventing post-traumatic stress disorder. Princeton, NJ: Princeton University Press. 